\title{
Methodology for Predicting the Service Life of Two-Ply Roofing-Felt Membrane
}

\author{
Erik Brandt ${ }^{1}$ and Martin Morelli ${ }^{2}$ \\ ${ }^{1}$ Department of the Built Environment, Aalborg University, A.C. Meyers Vaenge 15, 2450 \\ Copenhagen, Denmark, ebra@build.aau.dk \\ ${ }^{2}$ Department of the Built Environment, Aalborg University, A.C. Meyers Vaenge 15, 2450 \\ Copenhagen, Denmark, marmo@build.aau.dk
}

\begin{abstract}
The service life of roofs depends not only on the quality of materials and components but also on several other factors such as workmanship, maintenance, design and substrate. The service life of materials is at production time estimated to a certain number of years. Later when some experience has been gained the service life can hopefully be better predicted. However, the predicted service life can always be questioned because no one knows how long the product or material will last. The durability of a two-layer roofing-felt membrane has been investigated through inspection of several 20 to 30 years old roofs that had aged naturally under in use conditions in a northern humid climate. In $50 \%$ of the inspected roofs, samples were taken out for laboratory test. In this paper, the developed methodology to conduct a service life prediction of roofing membrane is presented. The paper includes a description of the on-site inspection; test conducted in the laboratory which was used as basis for predicting the service life of the two-layer roofing-felt membrane and how these information are extrapolated to a predicted service life. Further, it is discussed if the used methodology for prediction is generally applicable for other types of membranes.
\end{abstract}

Keywords: Natural Ageing, Prediction, Roofing Membrane, Building Survey.

\section{Introduction}

The service life of a flat membrane roof is dependent of the material of the membrane but to a large extent also on the design of details and the workmanship. Among the factors affecting the service life are the slope, the number of details, the buildability (how easy it is to build the roof including underlay and details). However, it is a prerequisite that the membrane itself has a long service life and it is the scope of this paper to propose a way to assess the service life of the membrane material. The influence of design, workmanship and maintenance is also influencing the service life of the finished roof, however is less influencing the service life of the roofingfelt membrane as a material.

In Denmark, we use a lot of different materials for roof coverings. For flat roofs (little slope) the traditional material is (bitumen based) roofing felt, which still has the major part of this market. PVC, TPO and other plastic materials only have a small market share.

As well, the membrane materials as the underlays have undergone large changes during the years. The roofing felt was originally a cheap material with a short service life that depended on regular maintenance. Later materials with better composition and better reinforcement were developed but still the service life was very short compared to other roof coverings. One of the reasons for this was that roofs were made without slope. This meant that the membranes were exposed to water for long periods and, even worse, that they - due to the many freezing point 
passages in Denmark - were exposed to forces from formation of ice. For some years, the service life for roofing felt in Denmark was only estimated to $12-15$ years.

In the beginning of the 1970ies the codes were changed, so a slope of at least 1:40 were required in order to avoid standing water and problems due to ice. Since then, lots of development as regards substrates for roofing membranes and composition (including reinforcement) of roofing felt have taken place. The roofing felts used today are almost exclusively modified bitumen (SBS or APP modified) with reinforcement of polyester (sometimes supplemented with small amounts of glass fibre).

Service life of roofing materials has been a subject of many heated discussions and so far, it has in Denmark not been possible to agree on reference service lives for different roofing materials.

Some roofing materials like clay tiles and zinc have been used for a long time and their service life is relatively well known due to long times experience from practice. For membranes the composition of the materials is changing rapidly and long-term experience are consequently not available. Estimation of service life must therefore be based on other methods e.g. accelerated ageing or estimation of service life based on the condition of roofs in practice (which naturally means that the roofs should have a relatively long time of service under in use conditions). In the following, we set forth how estimation of reference service life for a roofing felt was performed in Denmark and give proposal to a methodology for assessing estimation of service life for roofing membranes.

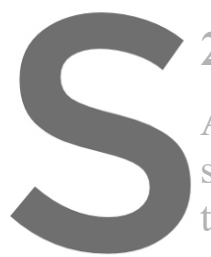

\section{Method}

As mentioned above estimatio

study, a combination

the reference service

The inspections were only related to the r
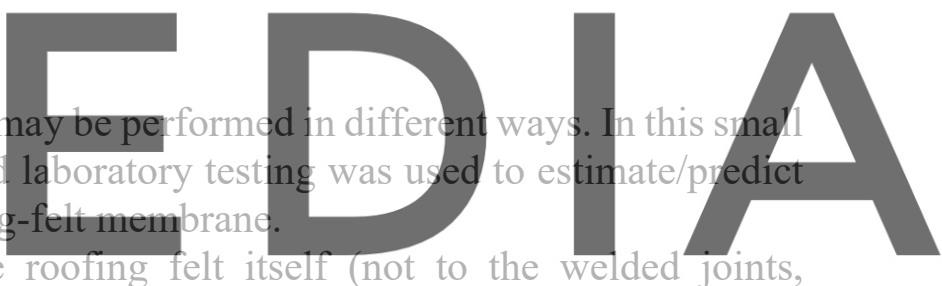

penetrations etc.). The roofs were located all oyer Denmark and had an inclination between

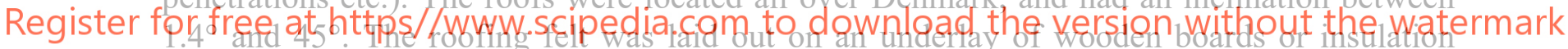

materials. The 12 inspected roofs were chosen randomly amongst several other roofs constructed in the period 1990 to 1999, i.e. 20-30 years old roofing-feit membranes. Amongst the criteria for selecting, the roof was the geographical location, size and accessibility. One roof was new when the roofing felt was installed and 11 roofs were renovations. The inspected roofs had a total area of 26'639 $\mathrm{m} 2$. The age and history of the inspected roofs were known as they belonged to a database run by a guarantee body, and the inspected roofs were chosen from this database. 


\subsection{Inspections}

Prior to the inspection, a systematic inspection scheme was developed to obtain a more consistent evaluation of the roofs. The evaluation of the different roof parameters, cf. Table 1, were ranked in four steps from a to $\mathrm{d}$, which described the condition of the roof as
a) in good conditions,
b) with minor degradation,
c) with critical degradation,
d) in need of replacement.

The general information were determined before the inspection and validated on site; however, if a sample was not cut out it could difficult to determine the buildup of the roof and the membrane layers.

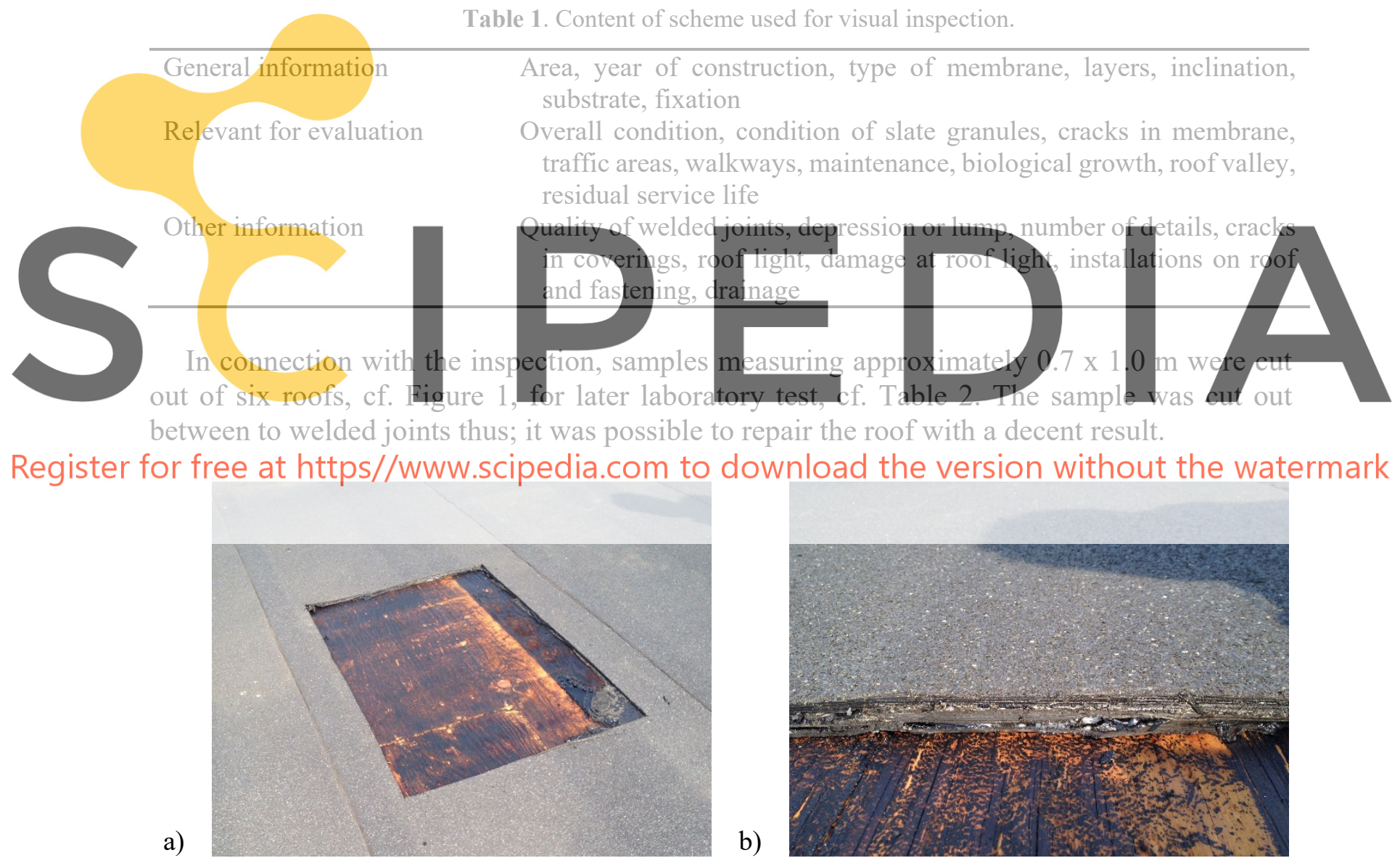

Figure 1. a) Test specimen cut out of roof with a wooden substrate and b) layers of welded roof membranes. 
Table 2. The test methods used for testing of samples.

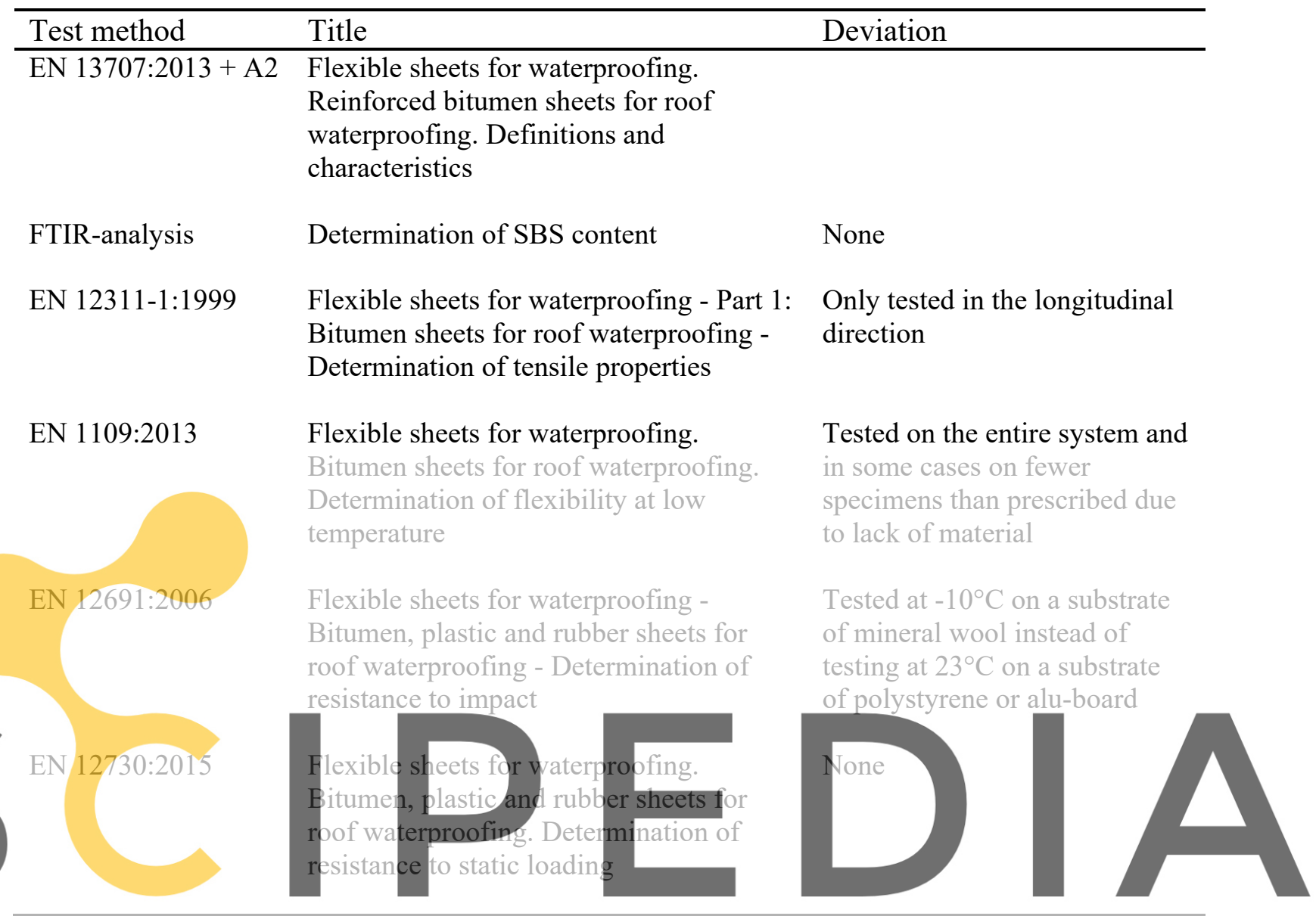

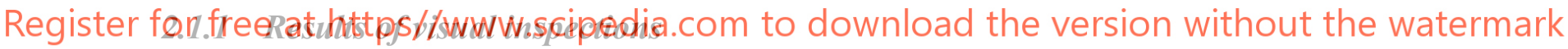

The results of the visual inspections are that the top membrane in all inspected roofs are assessed as being in good condition. Only minor changes compared to new membranes were visible. The protection in form of slate granules on the surface of the membrane was almost intact, and there were only minor signs of degradation even in valleys and depressions where water may gather occasionally (Figure $2 \mathrm{a}$ and $2 \mathrm{~b}$ ). There were in a few cases small cracks in the slate covering known as "mud cracks" - but even here, there were no signs of degradation of the bitumen below (Figure 3a). In no cases, there were seen degradation to an extent where the reinforcement was visible. There were no signs of shrinkage of the membrane during the inspections, and there were no signs of moisture problems (neither were there reported leaks or moisture problems). On the north facing coverings biological growth was often seen (Figure $3 b$ ), which can be eliminated with a regular maintenance. Biological growth was often observed on roofs that were not maintained, however, this did not indicate any signs of degradation of the raw top-roof membrane. 


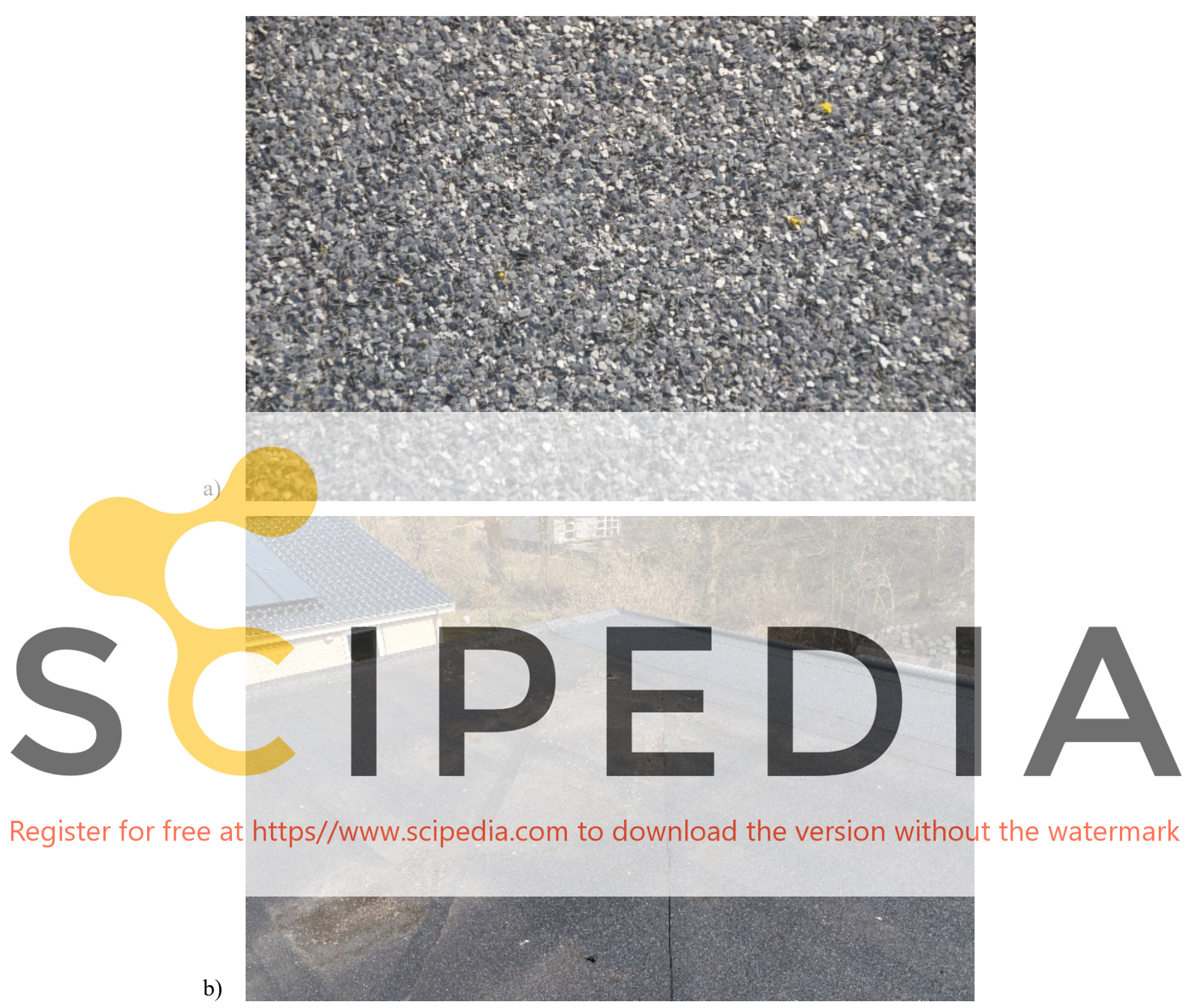

Figure 2. Roof condition at different points. a) Condition of slate is generally good as shown, b) roof valley in equal conditions as other parts of roof membrane.

\subsection{Laboratory Tests}

In Denmark, we have no legal requirements to the properties of roofing materials apart from the requirement of watertightness. There are on the other hand a number of properties that are normally considered when discussing bituminous roofing membranes. These include: tensile strength, elongation at break, flexibility under cold conditions and static and dynamic 

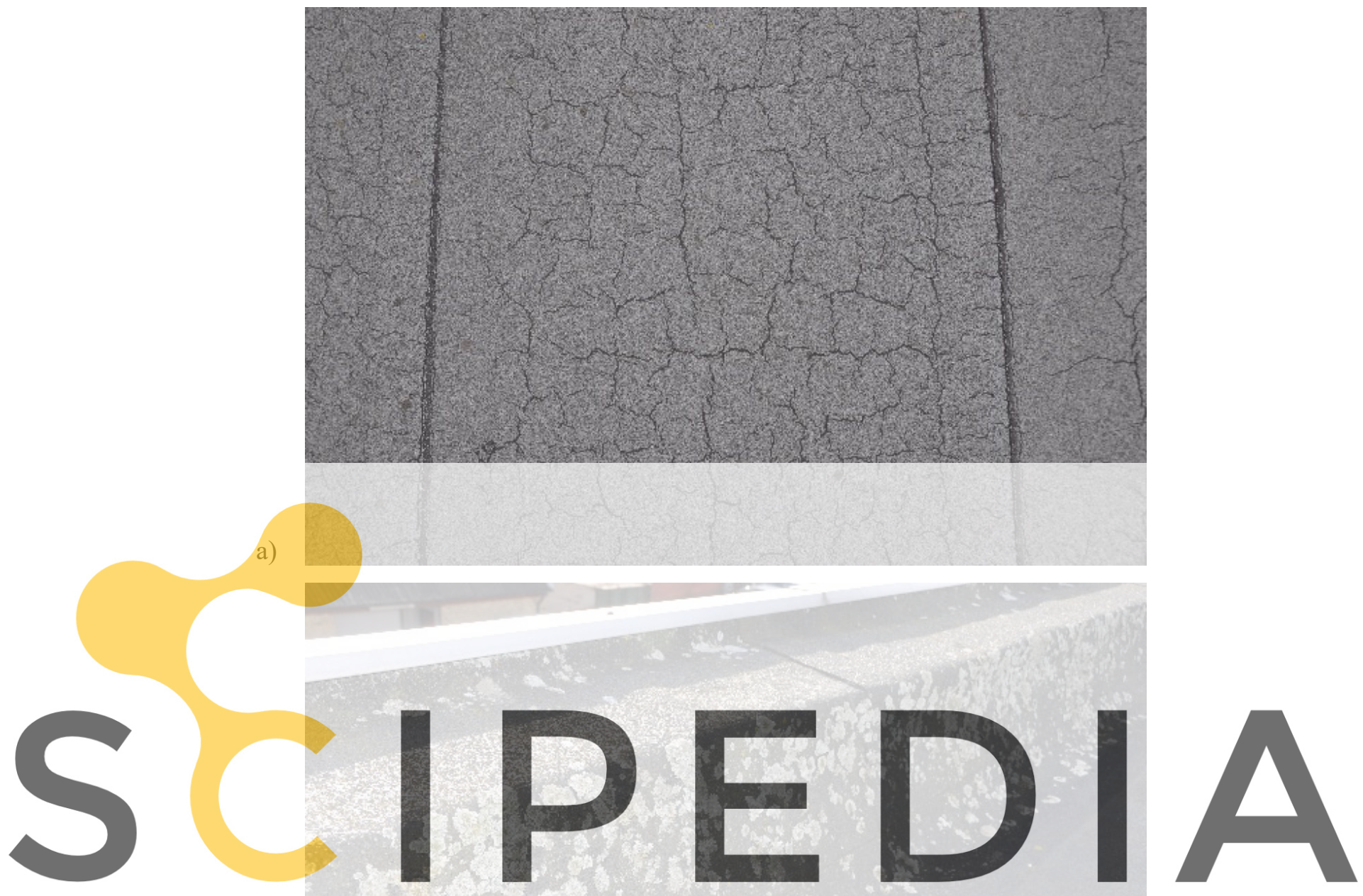

Register for free at https//www.scipedia.com to download the version without the watermark

b)

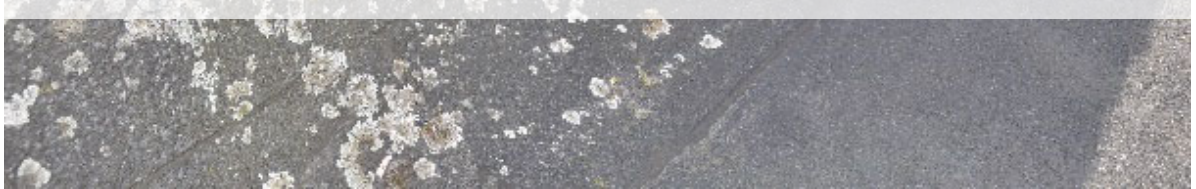

Figure 3. Roof condition at different points. a) mud crack with fine amount of slate granules and b) biological growth was seen on north facing covering and surfaces, this limited biological growth is assessed not to influence the service life.

load. It seemed natural to base the study on the above mentioned properties. The testing was performed on smaller samples taken from larger samples of $0.7 \times 1.0 \mathrm{~m}$ from the six roofs. The laboratory tests were conducted on the combined upper and lower roofing-felt membranes, because it was not possible to separate the two membranes. The results from the laboratory test were compared to a reference sample made from a virgin roofing felt (newly produced) as a combination with an upper and lower membrane welded together similar to the samples taken out from the inspected roofs.

The testing was performed at a laboratory that had all the necessary test facilities and was 
approved by ETA Denmark. The test facilities was inspected and the testing was supervised by SBi (the Danish Building Research Institute /Aalborg University) and ETA Denmark A/S (that afterwards issued an ETA based on the results of the investigation).

\subsubsection{Results of laboratory tests}

Tensile strength is often required to be above $500 \mathrm{~N} / 50 \mathrm{~mm}$ per sheet of bituminous roofing material and above $1000 \mathrm{~N} / 50 \mathrm{~mm}$ for a finished solution with two layers of membrane. This requirement was fulfilled for all the tested specimens.

Elongation at break: The results achieved during testing was all above normal used requirements in many other European countries.

For flexibility under cold conditions results under $-15^{\circ} \mathrm{C}$ were achieved for membranes aged 20-30 years under in use conditions i.e. better than the requirements used for new membranes after accelerated heat ageing (often considered to be equivalent to 10 years of natural ageing).

Testing for static and dynamic load was passed by all samples with results similar to those for virgin materials.

The SBS content in the tested membranes lies in the same range as by production and within the deviations that may be expected by the test method.

In general, all samples that were tested performed very close to the reference samples of virgin welded material.

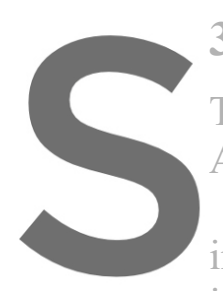

3 Service Life Prediction
There are no commonly accepted method to be used for prediction of service life based on tests
All predictions are consequently based on subjective judgements.
In this case the prediction of service life of the roofing membrand is based om yisual
inspections and tests in the laboratory. It is our opinion that both parts of the investigation are important and both should be taken into account when the service life shall be predicted. If one

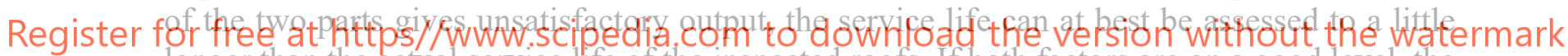
longer than the actual service life of the inspected roofs. If both factors are on a good level, the service life can be assessed to be longer than the actual service life of the inspected membranes - the question is only how much longer. This depends on the actual results of both inspections and laboratory tests. Both tests should be weighted equally important and all the investigated parameters determined in the laboratory.

In this study inspections as well as laboratory tests showed very good results. Based on the results the reference service life was estimated to at least 50 years. This result is in accordance with earlier studies in Denmark performed by the Danish Roofing Advisory Board (Brandt and Bunch-Nielsen, 2008) and results from Finnish investigations (Kattoliitto, n.d.).

\section{Discussion}

The methodology for prediction the service life of 2-ply roofing felt was in this case chosen as explained in 3 Service life prediction but other methodologies may be used if it appears more relevant. The laboratory test might have been complemented by other tests, cf. below, where it is explained why some test have not been part of this investigation.

Watertightness was not tested, as no leaks or moisture problems have been reported or noted 
in the roofs. Further, no leaks were detected after the tests for static and dynamic load.

Strength of connections were not tested as it was impossible to separate the layers in the finished membrane (two layers welded together).

Dimensional stability was not tested as this is most important the first few years after installation (shrinkage is unwanted at installation). There were no signs of shrinkage by the inspections.

Peel and shear resistance is not relevant for 2-ply systems according to EN 13707 table A.1.

\section{Conclusion}

In this study we used a methodology based on a combination of visual inspections of "old" roofs in situ and test of material properties of samples taken from the inspected roofs. It is our opinion that this method is well suited for estimation of reference service life of roofing membranes. It should be noted that it is a prerequisite that the roofs to be inspected should be relatively "old" compared to the final estimated result of service life. It is also necessary to know the history of the roof membranes i.e. to avoid estimation of roof membranes that has been repaired or replaced roof, thus it interfere with the results. We believe that the used methodology may be used for other types of roofing membranes and maybe even more generally for estimation of service life for building materials.

When it comes to the service life of the finished roof it is necessary to take into account also the influence of design, workmanship and maintenance. In Denmark, we have for quite a long

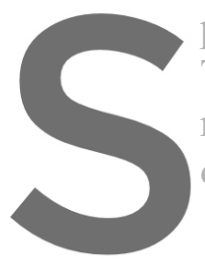
period used directions TOR and are published resulted in a significant directions help to desig In addition, the workmanship is importan considered crucial that skilled persons are used for the job.
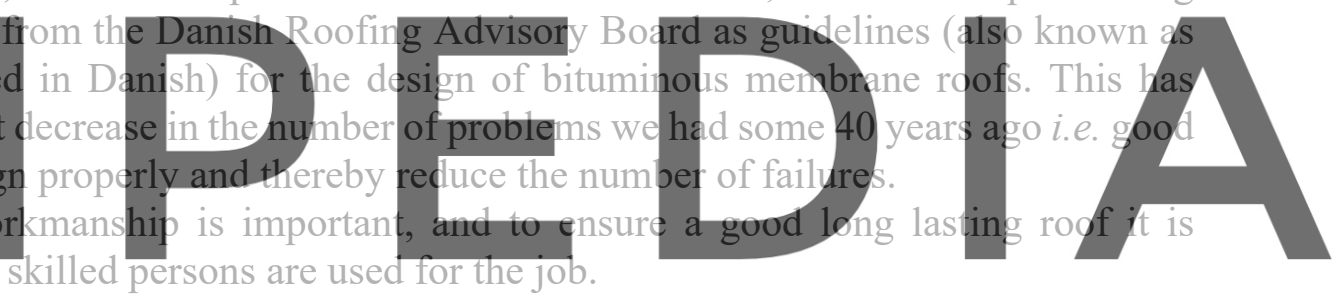

Register forfree at https//www.scipedia.com to download the version without the watermark

Erik Brandt: https://orcid.org/0000-0003-1485-5600

Miartin Morelit: https://orcid.org/0000-0002-1013-3136

\section{References}

Brandt, E. and Bunch-Nielsen, T. (2008). Service life (model) for bituminous roofing. In Proceedings of the 11 DBMC International Conference on Durability of Building Materials and Components, Istanbul, Turkey, T22, 1-9.

EN (1999). EN 12311-1:1999: Flexible sheets for waterproofing - Part 1: Bitumen sheets for roof waterproofing - Determination of tensile properties.

EN (2006). EN 12691:2006: Flexible sheets for waterproofing - Bitumen, plastic and rubber sheets for roof waterproofing - Determination of resistance to impact.

EN (2013a). EN 1109:2013: Flexible sheets for waterproofing. Bitumen sheets for roof waterproofing. Determination of flexibility at low temperature.

EN (2013b). EN 13707:2013: Flexible sheets for waterproofing. Reinforced bitumen sheets for roof waterproofing. Definitions and characteristics.

EN (2015). EN 12730:2015: Flexible sheets for waterproofing. Bitumen, plastic and rubber sheets for roof waterproofing. Determination of resistance to static loading.

Kattoliitto (n.d.). Roof System Manual. Kattoliitto, Finland. 